\title{
Genomic copy number and expression patterns in testicular germ
}

\section{cell tumours}

\author{
A Mclntyre ${ }^{1,4}$, B Summersgill ${ }^{1,4}$, YJ Lu ${ }^{1,5}$, E Missiaglia', S Kitazawa ${ }^{2}$, JW Oosterhuis ${ }^{3}$, LH Looijenga ${ }^{3}$ and \\ J Shipley*,I
}

'Molecular Cytogenetics, Section of Molecular Carcinogenesis, The Institute of Cancer Research, Sutton, Surrey, UK; ${ }^{2}$ Department of Molecular Pathology, Kobe University School of Medicine, Chuo-ku, Kobe, Japan; ${ }^{3}$ Department of Pathology, Erasmus MC-University Medical Center Rotterdam, Daniel den Hoed Cancer Center, Josephine Nefkens Institute, Rotterdam, The Netherlands

Testicular germ cell tumours of adults and adolescents (TGCT) include seminomas (SE) and nonseminomas (NS), with spermatocytic seminomas (SSE) representing a distinct entity in older men. SE and NS have gain of $12 \mathrm{p}$ material in all cases, whereas SSE are associated with overrepresentation of chromosome 9. Here, we compare at the chromosomal level, copy number imbalances with global expression changes, identified by comparative expressed sequence hybridisation analyses, in seven SE, one combined tumour, seven NS and seven cell lines. Positive correlations were found consistent with copy number as a main driver of expression change, despite reported differences in methylation status in SE and NS. Analysis of chromosomal copy number and expression data could not distinguish between SE and NS, in-keeping with a similar genetic pathogenesis. However, increased expression from 4q22, 5q23.2 and $9 p 21$ distinguished SSE from SE and NS and decreased copy number and expression from 2q36-q37 and 6q24 was a specific feature of NS-derived cell lines. Our analysis also highlights 19 regions with both copy number and expression imbalances in greater than $40 \%$ of cases. Mining available expression array data identified genes from these regions as candidates for involvement in TGCT development. Supplementary data is available at http://www.crukdmf.icr.ac.uk/array/array.html.

British Journal of Cancer (2007) 97, 1707-1712. doi:I0.1038/sj.bjc.6604079 www.bjcancer.com

Published online 4 December 2007

(c) 2007 Cancer Research UK

Keywords: testicular germ cell tumour; spermatocytic seminoma; chromosome; comparative genomic hybridisation; CESH

Adult germ cell tumours of the testis can be grouped by age of incidence and differentiation status into two main entities (Oosterhuis and Looijenga, 2005). Firstly, testicular germ cell tumours (TGCT) of adults and adolescents. These are the most common malignancy in males aged 20-40 years (Horwich et al, 1991 ) accounting for $60 \%$ of all male malignancies in this age group (Ulbright, 1993). TGCT can be classified into two main subtypes, seminoma (SE) and nonseminoma (NS). SE have a median age at diagnosis of 35 and resemble primordial germ cells (PGC)/gonocytes, the cells from which both these subtypes are generally thought to be derived. NS, which have a median age at diagnosis of 25, exhibit various stages of differentiation with cells from embryonic, extra-embryonic and somatic tissue types (Mostofi, 1973). Material from the short arm of chromosome 12 is invariably gained in these tumours and in roughly $10 \%$ of cases a

\footnotetext{
* Correspondence: J Shipley, Molecular Cytogenetics, Section of Molecular Carcinogenesis, The Institute of Cancer Research, I5 Cotswold Road, Sutton, Surrey SM2 5NG, UK;

E-mail: janet.shipley@icr.ac.uk

${ }^{4}$ These authors contributed equally to this work

${ }^{5}$ Current address: Department of Medical Oncology, Barts and London School of Medicine and Dentistry, Queen Mary, University of London, London, UK.

Revised 4 October 2007; accepted II October 2007; published online 4 December 2007
}

smaller region of gain at $12 \mathrm{p} 11.2-\mathrm{p} 12.1$ has been defined (Rodriguez et al, 2003; Zafarana et al, 2003).

Secondly, spermatocytic seminomas (SSE) are also testicular tumours of germ cell origin, however, they are generally restricted to men aged over 50 years (Oosterhuis and Looijenga, 2005). The genomic imprinting in SSE has a paternal pattern that is different to that of SE and NS, which generally show an erased pattern of imprinting. This is consistent with SSE being derived from a more differentiated germ cell in the spermatogenic lineage than SE or NS (Verkerk et al, 1997). Unlike the TGCT of adults and adolescents, gain of $12 \mathrm{p}$ material is not a feature of these tumours. However, gain of chromosome 9 is associated with SSE and array comparative genomic hybridisation analysis identified amplification of 9p21.3-ter and the likely involvement of the DMRT1 gene (Looijenga et al, 2006).

Cytogenetic, comparative genomic hybridisation (CGH) and allelic imbalance studies of SE and NS have shown that a number of regions in addition to $12 \mathrm{p}$ are imbalanced. Reported frequent aberrations common to both SE and NS include gain of material from chromosomes 1, 7, 8, 17, 21 and $\mathrm{X}$ and loss of material from chromosomes 4, 5, 11, 13, 18 and Y (van Echten et al, 1995; Korn et al, 1996; Mostert et al, 1996; Sandberg et al, 1996; Summersgill et al, 1998a, b; Kraggerud et al, 2002; von Eyben et al, 2004). In recent years, a number of expression profiling studies have been reported and these have identified overexpressed genes and expression signatures, which distinguish different subtypes of NS (Skotheim et al, 2005). Although we have previously examined 
gene copy number and expression changes associated with $12 \mathrm{p}$ (Rodriguez et al, 2003), few studies have integrated genomic and expression array data for the entire genome of TGCT (Skotheim et al, 2006). Factors predicted to influence gene expression include genomic copy number and epigenetic factors such as methylation. The level of methylation in TGCT varies between the subtypes and previous studies have found that SE have a lower level of $\mathrm{CpG}$ island methylation than NS (Smiraglia et al, 2002; Zhang et al, 2005).

Here, we investigate a series of SSE, SE, NS and cell lines using the approach of comparative expressed sequence hybridisation (CESH) (Lu et al, 2001) to determine a global chromosomal level view of the expression patterns in these tumours. This and CGH data are analysed to determine the relationship between expression patterns and copy number imbalances. In conjunction with published data for SE and NS, regions of imbalance associated with differentially expressed genes in greater than $40 \%$ of cases were identified. In addition, changes in expression are identified which differentiate between TGCT, NS-derived cell lines and SSE.

\section{MATERIALS AND METHODS}

Snap-frozen primary tumour samples were collected from histologically verified SE (26), NS (24), combined tumours (CT) (6) and SSE (5) obtained from patients attending the Royal Marsden Hospital NHS Trust and Erasmus MC University Medical Center, Rotterdam (Supplementary Table 1). Informed patient consent and ethical approval were obtained for the use of the material in this study in accordance with the Helsinki Declaration. In addition, nine cell lines derived from NS tumours and one derived from a SE were also included in the study. These were GCT27, GCT44, Tera1, Tera2, H12.2, 2102Ep, 577MF, NTERA2, SUSA and TCam-2. The cell lines were cultured as described previously (Pera et al, 1987; Kelland et al, 1992; Mizuno et al, 1993; Summersgill et al, 2001; Goddard et al, 2007). A pool of 45 individual samples of normal testis RNA was available from Clontech (Mountain View, CA, USA) and normal DNA from Sigma (St Louis, MO, USA). Information as to which samples were studied by CGH and CESH can be found in Supplementary Table 1 at http://www.crukdmf.icr.ac.uk/array/array.html.

\section{Comparative genomic hybridisation}

CGH was performed as described previously (Summersgill et al, 1998 b) using genomic DNA prepared by standard procedures from patient tissue, cell lines, together with normal reference DNA. Images were captured using a cooled CCD Photometrics camera with SmartCapture software (Digital Scientific, Cambridge, UK). Image analysis was carried out using Quips-XL software (Vysis Inc., Des Plaines, IL, USA). At least five representative images were fully analysed and the results from these were studied separately and also combined to produce an average fluorescence ratio for each chromosome. A copy number change was indicated when the average fluorescence ratio lay outside the normal range which was determined in control experiments using differentially labelled normal DNA.

\section{Comparative expressed sequence hybridisation}

$\mathrm{CESH}$ analysis was carried out as described previously (Lu et al, 2001) using the same capture system and software as for CGH analysis. Five good quality metaphases with 320-450 band resolution were analysed for each case using the Quips CGH analysis software (Vysis) to produce an average profile of the fluorescence intensity ratios. Unlike $\mathrm{CGH}$, the $\mathrm{CESH}$ ratios of fluorescence frequently change within a small chromosomal region. Misalignment in averaged profiles can reduce resolution and therefore two or three metaphases with less condensed chromosomes (around 700 band resolution) were also examined individually to precisely define chromosome bands containing differentially expressing genes.

\section{Data analysis}

Gain and loss of chromosomal regions from CGH and gene overand underexpression from CESH analysis were recorded in Excel spreadsheet format. For each chromosomal band, gain/overexpression was indicated by 1 , loss/underexpression by -1 and no change by 0 . From this the frequency of aberrations could be calculated. The data, which were subject to unsupervised clustering analysis, were collected using Clustan (http://www.clustan.com). The data were also subject to supervised learning method PAM (prediction analysis for microarray) (Tibshirani et al, 2002), which was used to identify expression pattern associated with specific histology. This is carried out by a penalised $t$-statistic, which ranks the elements and a soft-thresholding to identify the set of overexpress regions for classification. To analyse correlations between copy number and expression data the Spearman's rho test was used.

\section{RESULTS}

\section{Identification of regions of frequent copy number and expression alteration}

26 SE-, 6 CT-, 24 NS- and 7 NS-derived cell lines were investigated by metaphase CGH. 7 SE-, 1 CT-, 7 NS- and 9 NS-derived cell lines, 1 SE-derived cell line and 5 SSE were investigated by CESH. Metaphase CGH and CESH data were divided based on subtype and the frequency of aberrations at each chromosomal region was calculated. Frequency plots of imbalances can be seen in Figure 1 . Regions of copy number and expression imbalance, which had a frequency of greater than $40 \%$ were identified. This identified 42 regions of copy number and 50 regions of expression in addition to the $12 \mathrm{p}$ in SE-, NS-, NS-derived cell lines. Analysis of SSE CESH data determined 43 regions of expression imbalance. Comparison between the copy number and expression data highlighted the importance of 20 regions denoted in Table 1. These regions had overlapping copy number and expression imbalances in SE, NS or TGCT cell lines. All identified regions of copy number and expression imbalance can be seen in Supplementary Tables 2 (CGH data) and 3 (CESH data)(http://www.crukdmf.icr.ac.uk/ array/array.html).

\section{Identification of regions that are significantly different between tumour subtypes}

Supervised learning of the SE, CT, NS and cell lines CGH data found that loss of two regions at $22 \mathrm{q} 11-\mathrm{q} 13.3$ and $2 \mathrm{q} 14.1-\mathrm{q} 31$ were associated with the cell lines. No other differences were found or could be determined with unsupervised clustering. Prediction analysis of the CESH data could not find significant differences between the SE and NS. However, differences in expression patterns between the primary TGCT (SE and NS), cell lines and SSE were found (Figure 2). These included 12p11-p13.3, which was overexpressed in SE, NS and cell lines but not in SSE. The chromosome bands 2q31, 2q35, 2q36 and 2q37 were associated with overexpression in SE, NS and SSE but underexpression in cell lines. Overexpression from 4q22 and 9p21 was associated with SSE.

\section{Relationship between copy number and expression in SE and NS}

To determine any relationship between the copy number and expression alterations correlations between the parallel CGH and 
A

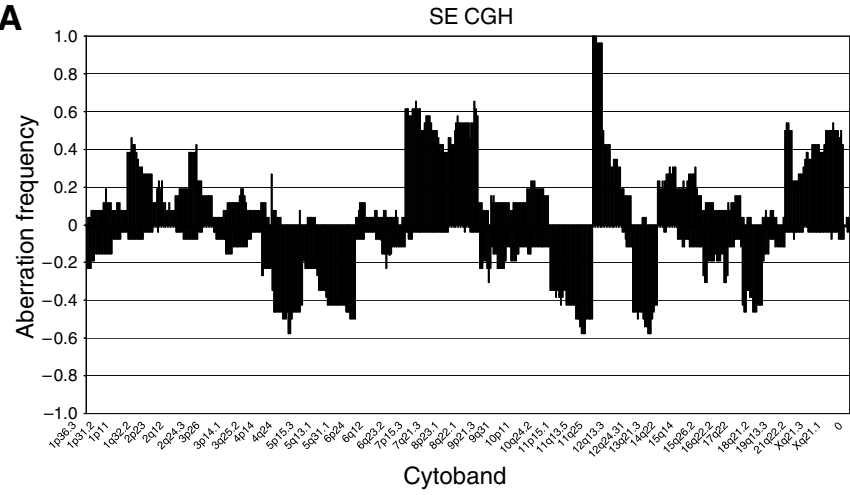

C

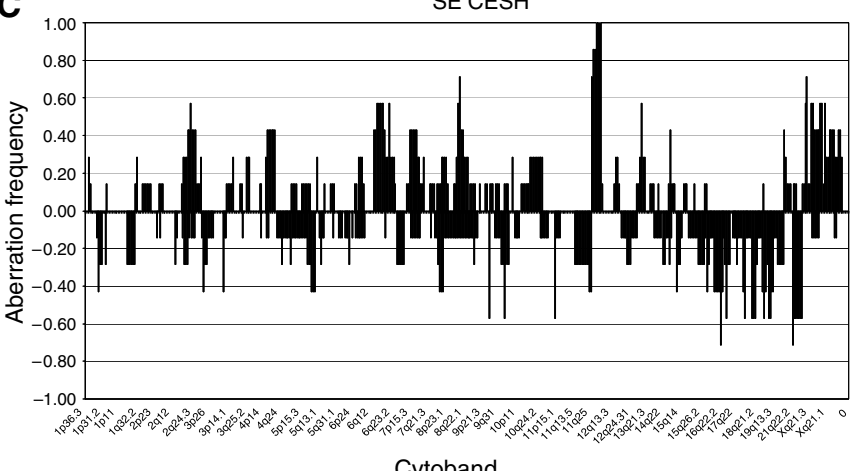

Cytoband

E
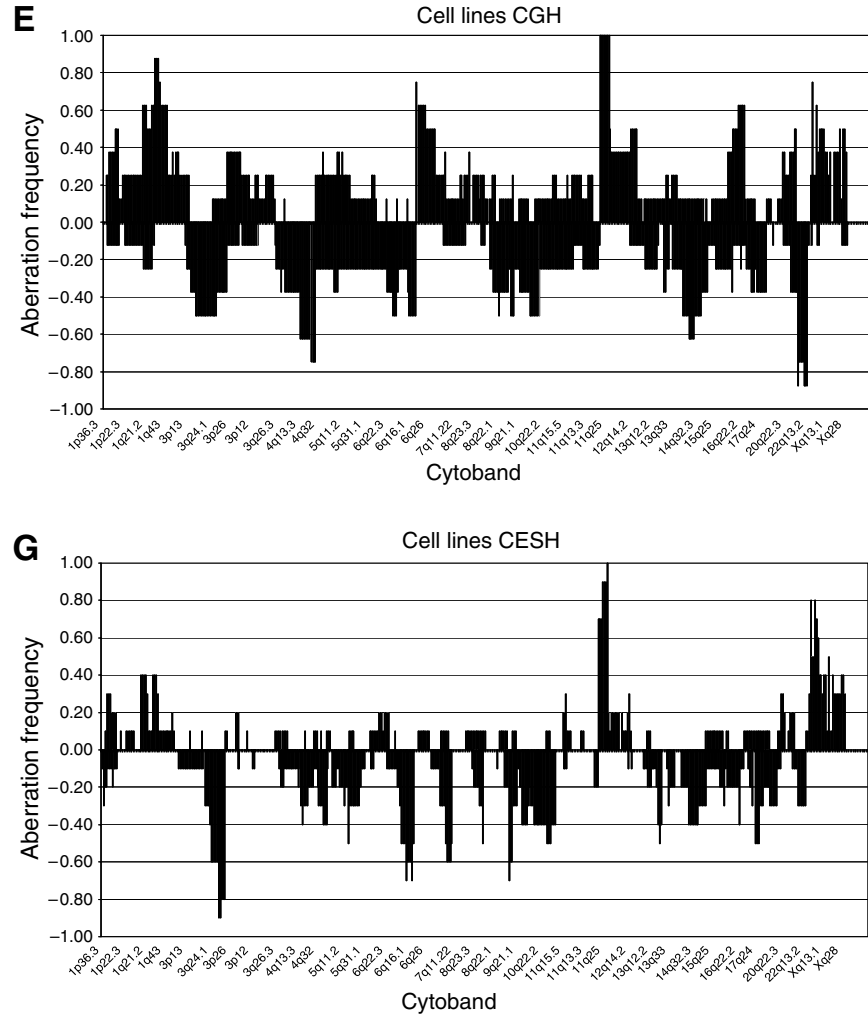

B

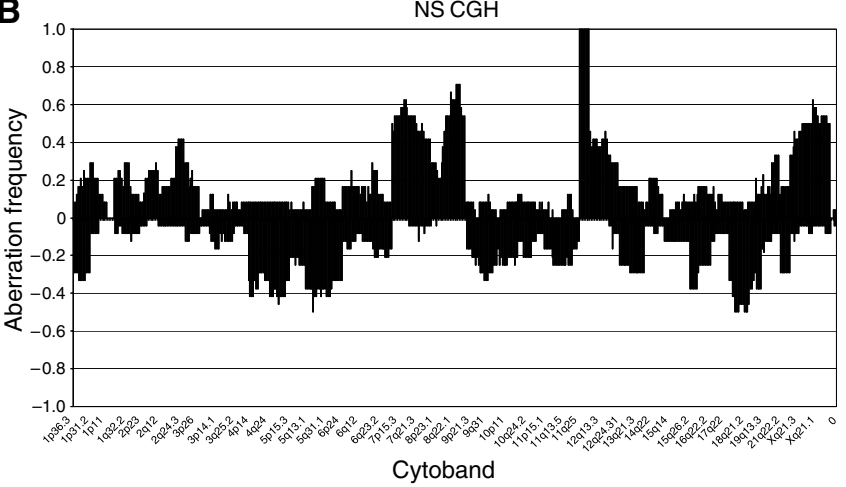

D

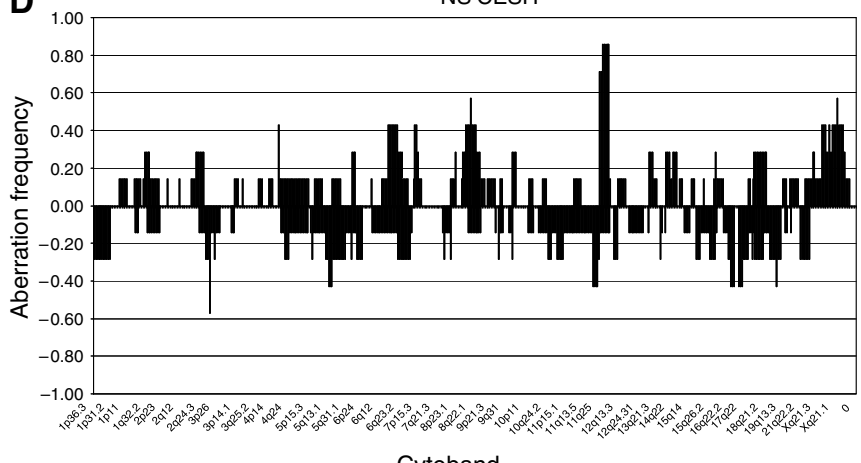

Cytoband

$\mathbf{F}$

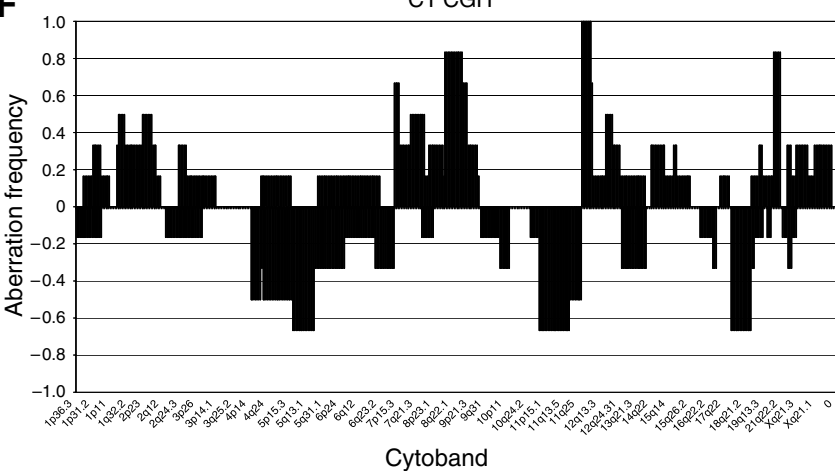

H

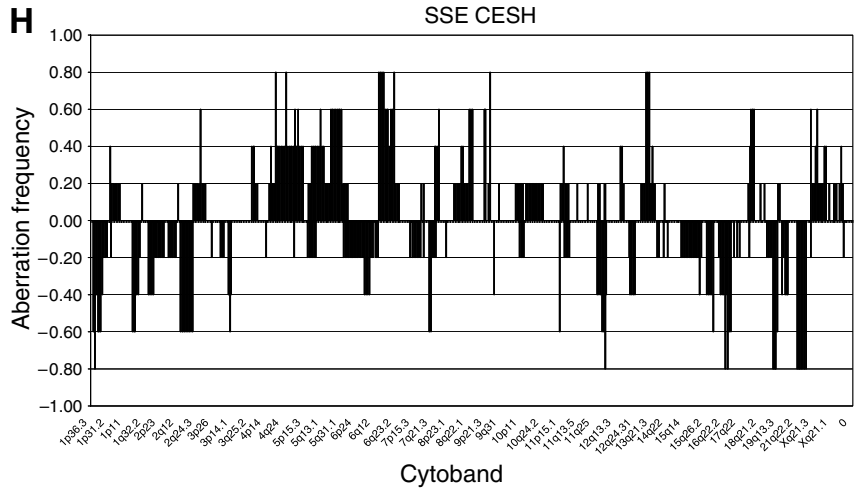

Figure I Frequency plots of copy number and expression imbalances in the different subtypes. The frequency of copy number and expression aberrations ( $X$-axis) is plotted against the chromosomal location ( $Y$ axis) for each subtype. Graphs show the proportion of samples, which have copy number or expression aberrations where a positive frequency is equal to proportion of samples with increased copy number or expression and negative frequency equal to the proportion of samples with decreased copy number or expression at each chromosome cytoband. 26 SE, 24 NS, 6 CT and 7 cell lines were analysed by CGH. 7SE, 7NS, 10 cell lines and 5 SSE were analysed by CESH. (A), (B), (E) and $(\mathbf{F})$ are the frequency plots for copy number aberrations determined by CGH for SE, NS, TGCT cell lines and combined tumours, respectively. $(\mathbf{C}),(\mathbf{D}),(\mathbf{G})$ and $(\mathbf{H})$ are the frequency plots for expression changes determined by CESH for SE, NS, TGCT cell lines and SSE, respectively. 
Table I Regions of overlapping copy number and expression imbalance with a frequency of greater than $40 \%$

\begin{tabular}{|c|c|c|c|c|c|c|c|}
\hline CGH & Frequency & CESH & Frequency & CGH & Frequency & CESH & Frequency \\
\hline $2 \mathrm{q} 31$ & 42 & $2 \mathrm{q} 31$ & 43 & $1|q| 2-q 25$ & 58 & $1 \mathrm{q} 24-\mathrm{q} 25$ & 43 \\
\hline $7 p 22-q 36$ & 65 & $7 p|5.3-p| 3$ & 43 & $|8 p||.32-p| \mid .2$ & 46 & $|8 p| 1.2$ & 57 \\
\hline$|2 p| 3.3-q \mid 3.3$ & 100 & $|2 p| 2.3-p||$ & 100 & & & & \\
\hline $2|q| \mid-q 22.3$ & 54 & $2|q| \mid$ & 43 & & & & \\
\hline Xp22.3-p22.1 & 45 & $\times p 21.3$ & 71 & & & & \\
\hline \multicolumn{4}{|l|}{ NS gain } & NS loss & & & \\
\hline $7 p 22-q 36$ & 63 & $7 p 21.1-p 21.2$ & 43 & $5 q 14-q 21.1$ & 50 & $5 q|3.1-q| 3.3$ & 43 \\
\hline $8 \mathrm{q} 12-\mathrm{q} 24.3$ & 70 & $8 \mathrm{q}_{21}$ & 57 & & & & \\
\hline$|2 p| 3.3-p||$ & 100 & $|2 p| 3.1-p||$ & 86 & & & & \\
\hline Xp | I.4-q28 & 63 & Xp|l.22-pll.21 & 43 & & & & \\
\hline Xp। I.4-q28 & 54 & Xq22.1 & 57 & & & & \\
\hline Xp21.3 & 75 & Xp21.3 & 80 & $9 q 31-q 33$ & 57 & $9 q 31$ & 70 \\
\hline \multirow{3}{*}{ Xp। I.4-q27 } & 63 & Xpll.4 & 80 & $10 \mathrm{q} \mid 1-\mathrm{q} 22.3$ & 50 & $|0 p| 2.3-p||$ & 44 \\
\hline & & & & $|5 q| \mid-q 24$ & 63 & $15 q 21-q 23$ & 40 \\
\hline & & & & $18 q 21.2-q 23$ & 50 & $|8 q 2| . \mid-q 21.3$ & 56 \\
\hline
\end{tabular}

$\mathrm{CESH}=$ comparative expressed sequence hybridisation; $\mathrm{CGH}=$ comparative genomic hybridisation; $\mathrm{SE}=$ seminoma; NS = non-seminoma. $26 \mathrm{SE}, 24 \mathrm{NS}$ and 7 cell lines were analysed by CGH. 7SE, 7NS and 10 cell lines were analysed by CESH.

\section{A SE+NS Cell lines SSE}
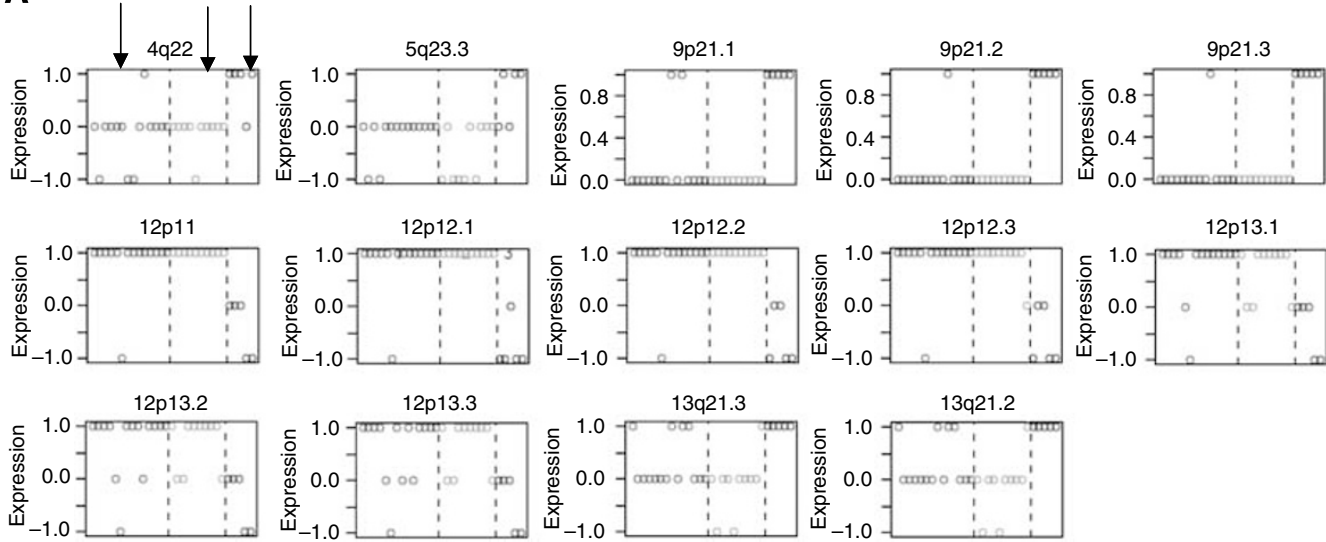

B
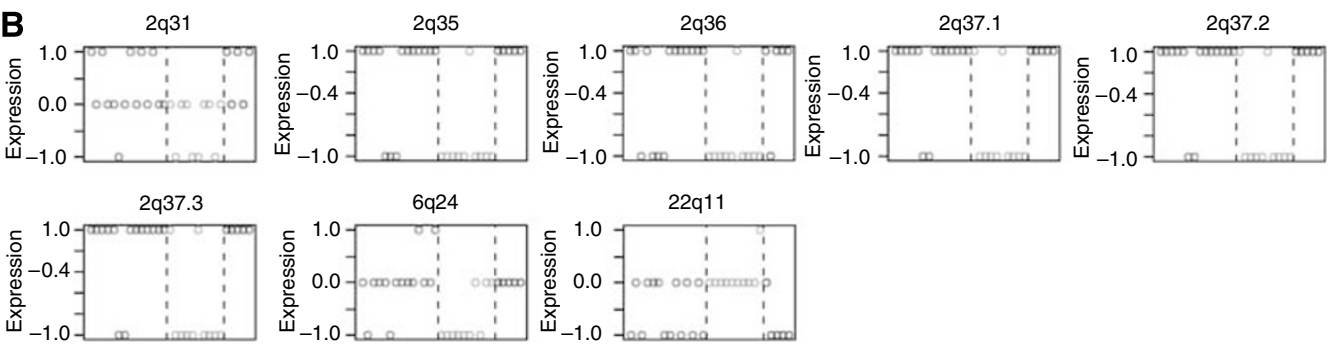

Figure 2 Supervised learning of CESH data. (A) Loci that are differentially expressed between TGCT and SSE. (B) Loci that are differentially expressed between primary tumours and cell lines. Each box plot represents a chromosome locus identified as discriminatory between the groups, separated by dashed lines. Group I (left): primary SE and NS samples; Group 2 (middle): NS-derived cell lines; Group 3 (right): primary SSE samples. Each circle represents a sample within that group. The axis indicates the expression of each sample where I denotes increased expression; 0 normal and - I decreased expression.

CESH data were tested using Spearman's rho test. All the primary tumours and cell lines except one NS primary sample showed a significant correlation. The Spearman's rho correlation coefficients ranged from 0.089 to 0.719 with an average of 0.267 . There was no significant difference in the strength of the correlation between the subtypes or their differentiation status using the student's $t$-test. 
The data analysis revealed no difference in the association of copy number and expression changes between regions of gain or loss.

\section{DISCUSSION}

Our analysis of copy number and associated differential expression highlights regions likely to be involved in TGCT development. It also illustrates molecular similarities and differences between types and subtypes of these tumours. We identified three novel regions $(2 \mathrm{q} 31,18 \mathrm{p} 11.2$ and $21 \mathrm{q} 11)$ of copy number and expression change in SE and NS. We also defined differential expression to single cytogenetic bands within a number of regions previously characterised with frequent copy number changes.

Three regions showed copy number and expression changes at a high frequency that were consistent with our previous array CGH study of TGCT (McIntyre et al, 2004). These regions are 7p22 (0.87$2.02 \mathrm{Mb}), 8 \mathrm{q} 21(86.46-90.69 \mathrm{Mb})$ and Xq22 (101.54-101.71). Overexpression from 8q21 was found at particularly high frequency involving $71 \%$ of SE and $57 \%$ of NS. The $8 \mathrm{q} 21$ region is frequently gained and amplified in other tumour types, including breast, lung and ovarian cancer (Balleine et al, 2000; Byrne et al, 2005; Zhu et al, 2007). Tumour protein D52 isoform 2 (TPD52) encoded by a gene at $8 \mathrm{q} 21.1$ is described as the target for amplification of this region in breast and ovarian cancers (Balleine et al, 2000; Byrne et al, 2005). Mining of published expression microarray data for TGCTs (Sperger et al, 2003) revealed increased expression of TPD52 in TGCT compared to normal testis with an average fold increase of 3.2 and represents a good candidate for involvement in TGCT. Other differentially expressed genes in regions of imbalance were identified including cell division cycle associated 7 (CDCA7) localised to $2 \mathrm{q} 31$, which had an average 4.9-fold increase in expression compared with normal testis. CDCA7 is a downstream target of MYC and is frequently overexpressed in human cancers (Osthus et al, 2005).

Prediction analysis using the regions of differential expression in TGCT subtypes identified discriminating regions in the SSE, TGCT samples and cell lines. These regions included known differences of $12 \mathrm{p}$ overexpression associated with TGCT (Rodriguez et al, 2003) and 9p21 associated with SSE (Looijenga et al, 2006). Novel differences included overexpression from 4q22 and 5q23.2 associated with SSE. Prediction analysis also highlighted differences between TGCT cell lines and primary tumours at both the copy number and expression levels. These differences may reflect their adaptive response to in vitro culturing and limit their usefulness as models of TGCT. However, the majority of regions found in primary tumour material were also found in the cell lines (Table 1; Supplementary Tables 2 and 3).

Our analysis could not find any difference at the genomic or expression level between the SE and NS studied. This provides further evidence that the two subtypes have a similar genetic pathogenesis. Consistent with this is the high incidence of combined tumours $(\sim 10 \%)$, which contain elements of both subtypes, and evidence supporting development of NS from SE (Raja et al, 1992). Many regions of differential expression were similar in the SSE and the TGCT of adults and adolescents. This may reflect the male germ cell origin of these tumours, which is proposed to differ only in differentiation status between the SSE and TGCT (Oosterhuis and Looijenga, 2005).

Although variable correlation coefficients were found between copy number and expression imbalances, there was a positive correlation in nearly all cases. This indicates that copy number imbalances have a strong effect on the expression patterns and are a major mechanism for aberrant expression in the majority of these tumours. No significant differences were identified in the strength of the correlations between expression and genomic copy number in the different subtypes and in differentiated $v s$ nondifferentiated tumours. This may suggest that the total effect on expression levels of mechanisms other than chromosomal imbalances is similar in the different subtypes of TGCT. This is despite reported differences in the frequency of $\mathrm{CpG}$ island methylation of $0.08 \%$ in SE compared to $1.11 \%$ in NS (Smiraglia et al, 2002; Zhang et al, 2005).

A number of regions of copy number change were not associated with an expression change. Similarly, a number of regions were found to have expression changes, but no copy number changes. Similar patterns were found in a study of the metaphase CGH data and expression array data for the preinvasive stage of TGCT of adults and adolescents (Almstrup et al, 2005). Many of the genes found overexpressed without associated aberrant copy number are involved in maintenance of pluripotency (e.g. POU5F1 and NANOG) and are also highly expressed in PGCs (Almstrup et al, 2005). This is likely to reflect the embryonic stem cell-like nature of these tumours rather than a de novo change associated with development of the tumour.

The results presented here highlight correlations between genomic changes and global expression patterns, which suggests that copy number changes play a major role in the expression levels of genes from particular loci in TGCT. Expression patterns showed both similarities and differences at specific regions in TGCT, SSE and derived cell lines. This likely reflects their genetic pathogenesis and common cellular origin. We have defined a number of chromosome regions with a high frequency of both copy number and expression change in TGCT. These require further investigation to implicate oncogenes and tumour suppressor genes in the development of these tumours.

\section{ACKNOWLEDGEMENTS}

We thank Hans Stoop and Ad J.M. Gillis (Department of Pathology, Erasmus MC, Rotterdam, The Netherlands) for their contribution and also Martin Pera for providing the cell line GCT27. This study was supported by Cancer Research UK.

Supplementary Information accompanies the paper on British Journal of Cancer website (http://www.nature.com/bjc)

\section{REFERENCES}

Almstrup K, Ottesen AM, Sonne SB, Hoei-Hansen CE, Leffers H, Rajpert-De Meyts E, Skakkebaek NE (2005) Genomic and gene expression signature of the pre-invasive testicular carcinoma in situ. Cell Tissue Res 322: $159-165$

Balleine RL, Fejzo MS, Sathasivam P, Basset P, Clarke CL, Byrne JA (2000) The hD52 (TPD52) gene is a candidate target gene for events resulting in increased 8q21 copy number in human breast carcinoma. Genes Chromosomes Cancer 29: 48-57

Byrne JA, Balleine RL, Schoenberg Fejzo M, Mercieca J, Chiew YE, Livnat Y, St Heaps L, Peters GB, Byth K, Karlan BY, Slamon DJ, Harnett P, Defazio
A (2005) Tumor protein D52 (TPD52) is overexpressed and a gene amplification target in ovarian cancer. Int J Cancer 117: $1049-1054$

Goddard NC, McIntyre A, Summersgill B, Gilbert D, Kitazawa S, Shipley J (2007) KIT and RAS signalling pathways in testicular germ cell tumours: new data and a review of the literature. Int J Androl 30: 337-349

Horwich A, Dearnaley DP, Nicholls J, Jay G, Mason M, Harland S, Peckham MJ, Hendry WF (1991) Effectiveness of carboplatin, etoposide, and bleomycin combination chemotherapy in good-prognosis metastatic testicular nonseminomatous germ cell tumors. J Clin Oncol 9: $62-69$ 
Kelland LR, Mistry P, Abel G, Freidlos F, Loh SY, Roberts JJ, Harrap KR (1992) Establishment and characterization of an in vitro model of acquired resistance to cisplatin in a human testicular nonseminomatous germ cell line. Cancer Res 52: $1710-1716$

Korn WM, Oide Weghuis DE, Suijkerbuijk RF, Schmidt U, Otto T, du Manoir S, Geurts van Kessel A, Harstrick A, Seeber S, Becher R (1996) Detection of chromosomal DNA gains and losses in testicular germ cell tumors by comparative genomic hybridization. Genes Chromosomes Cancer 17: 78-87

Kraggerud SM, Skotheim RI, Szymanska J, Eknaes M, Fossa SD, Stenwig AE, Peltomaki P, Lothe RA (2002) Genome profiles of familial/bilateral and sporadic testicular germ cell tumors. Genes Chromosomes Cancer 34: $168-174$

Looijenga LH, Hersmus R, Gillis AJ, Pfundt R, Stoop HJ, van Gurp RJ, Veltman J, Beverloo HB, van Drunen E, van Kessel AG, Pera RR, Schneider DT, Summersgill B, Shipley J, McIntyre A, van der Spek P, Schoenmakers E, Oosterhuis JW (2006) Genomic and expression profiling of human spermatocytic seminomas: primary spermatocyte as tumorigenic precursor and DMRT1 as candidate chromosome 9 gene. Cancer Res 66: 290 - 302

Lu YJ, Williamson D, Clark J, Wang R, Tiffin N, Skelton L, Gordon T, Williams R, Allan B, Jackman A, Cooper C, Pritchard-Jones K, Shipley J (2001) Comparative expressed sequence hybridization to chromosomes for tumor classification and identification of genomic regions of differential gene expression. Proc Natl Acad Sci USA 98: 9197-9202

McIntyre A, Summersgill B, Jafer O, Rodriguez S, Zafarana G, Oosterhuis JW, Gillis AJ, Looijenga L, Cooper C, Huddart R, Clark J, Shipley J (2004) Defining minimum genomic regions of imbalance involved in testicular germ cell tumors of adolescents and adults through genome wide microarray analysis of cDNA clones. Oncogene 23: 9142-9147

Mizuno Y, Gotoh A, Kamidono S, Kitazawa S (1993) Establishment and characterization of a new human testicular germ cell tumor cell line (TCam-2). Nippon Hinyokika Gakkai Zasshi 84: 1211-1218

Mostert MM, van de Pol M, Olde Weghuis D, Suijkerbuijk RF, Geurts van Kessel A, van Echten J, Oosterhuis JW, Looijenga LH (1996) Comparative genomic hybridization of germ cell tumors of the adult testis: confirmation of karyotypic findings and identification of a 12p-amplicon. Cancer Genet Cytogenet 89: 146-152

Mostofi FK (1973) Proceedings: testicular tumors. Epidemiologic, etiologic, and pathologic features. Cancer 32: 1186-1201

Oosterhuis JW, Looijenga LH (2005) Testicular germ-cell tumours in a broader perspective. Nat Rev Cancer 5: 210-222

Osthus RC, Karim B, Prescott JE, Smith BD, McDevitt M, Huso DL, Dang CV (2005) The Myc target gene JPO1/CDCA7 is frequently overexpressed in human tumors and has limited transforming activity in vivo. Cancer Res 65: $5620-5627$

Pera MF, Blasco Lafita MJ, Mills J (1987) Cultured stem-cells from human testicular teratomas: the nature of human embryonal carcinoma, and its comparison with two types of yolk-sac carcinoma. Int J Cancer 40: 334-343

Raja MA, Oliver RT, Badenoch D, Blandy JP (1992) Orchidopexy and transformation of seminoma to non-seminoma. Lancet 339: 930

Rodriguez S, Jafer O, Goker H, Summersgill BM, Zafarana G, Gillis AJ, van Gurp RJ, Oosterhuis JW, Lu YJ, Huddart R, Cooper CS, Clark J, Looijenga LH, Shipley JM (2003) Expression profile of genes from 12p in testicular germ cell tumors of adolescents and adults associated with $\mathrm{i}(12 \mathrm{p})$ and amplification at 12p11.2-p12.1. Oncogene 22: 1880-1891

Sandberg AA, Meloni AM, Suijkerbuijk RF (1996) Reviews of chromosome studies in urological tumors. III. Cytogenetics and genes in testicular tumors. J Urol 155: $1531-1556$
Skotheim RI, Autio R, Lind GE, Kraggerud SM, Andrews PW, Monni O, Kallioniemi O, Lothe RA (2006) Novel genomic aberrations in testicular germ cell tumors by array-CGH, and associated gene expression changes. Cell Oncol 28: $315-326$

Skotheim RI, Lind GE, Monni O, Nesland JM, Abeler VM, Fossa SD, Duale N, Brunborg G, Kallioniemi O, Andrews PW, Lothe RA (2005) Differentiation of human embryonal carcinomas in vitro and in vivo reveals expression profiles relevant to normal development. Cancer Res 65: $5588-5598$

Smiraglia DJ, Szymanska J, Kraggerud SM, Lothe RA, Peltomaki P, Plass C (2002) Distinct epigenetic phenotypes in seminomatous and nonseminomatous testicular germ cell tumors. Oncogene 21: 3909-3916

Sperger JM, Chen X, Draper JS, Antosiewicz JE, Chon CH, Jones SB, Brooks JD, Andrews PW, Brown PO, Thomson JA (2003) Gene expression patterns in human embryonic stem cells and human pluripotent germ cell tumors. Proc Natl Acad Sci USA 100: 13350-13355

Summersgill B, Goker H, Osin P, Huddart R, Horwich A, Fisher C, Shipley J (1998a) Establishing germ cell origin of undifferentiated tumors by identifying gain of $12 \mathrm{p}$ material using comparative genomic hybridization analysis of paraffin-embedded samples. Diagn Mol Pathol 7: $260-266$

Summersgill B, Goker H, Weber-Hall S, Huddart R, Horwich A, Shipley J (1998b) Molecular cytogenetic analysis of adult testicular germ cell tumours and identification of regions of consensus copy number change. Br J Cancer 77: 305-313

Summersgill BM, Jafer O, Wang R, Goker H, Niculescu-Duvaz I, Huddart R, Shipley J (2001) Definition of chromosome aberrations in testicular germ cell tumor cell lines by 24-color karyotyping and complementary molecular cytogenetic analyses. Cancer Genet Cytogenet 128: 120 -129

Tibshirani R, Hastie T, Narasimhan B, Chu G (2002) Diagnosis of multiple cancer types by shrunken centroids of gene expression. Proc Natl Acad Sci USA 99: 6567-6572

Ulbright TM (1993) Germ cell neoplasms of the testis. Am J Surg Pathol 17: $1075-1091$

van Echten J, Oosterhuis JW, Looijenga LH, van de Pol M, Wiersema J, te Meerman GJ, Schaffordt Koops H, Sleijfer DT, de Jong B (1995) No recurrent structural abnormalities apart from $\mathrm{i}(12 \mathrm{p})$ in primary germ cell tumors of the adult testis. Genes Chromosomes Cancer 14: 133-144

Verkerk AJ, Ariel I, Dekker MC, Schneider T, van Gurp RJ, de Groot N, Gillis AJ, Oosterhuis JW, Hochberg AA, Looijenga LH (1997) Unique expression patterns of $\mathrm{H} 19$ in human testicular cancers of different etiology. Oncogene 14: 95-107

von Eyben FE, Jacobsen GK, Rorth M, Von Der Maase H (2004) Microinvasive germ cell tumour (MGCT) adjacent to testicular germ cell tumours. Histopathology 44: 547-554

Zafarana G, Grygalewicz B, Gillis AJ, Vissers LE, van de Vliet W, van Gurp RJ, Stoop H, Debiec-Rychter M, Oosterhuis JW, van Kessel AG, Schoenmakers EF, Looijenga LH, Veltman JA (2003) 12p-amplicon structure analysis in testicular germ cell tumors of adolescents and adults by array CGH. Oncogene 22: 7695-7701

Zhang C, Kawakami T, Okada Y, Okamoto K (2005) Distinctive epigenetic phenotype of cancer testis antigen genes among seminomatous and nonseminomatous testicular germ-cell tumors. Genes Chromosomes Cancer 43: $104-112$

Zhu H, Lam DC, Han KC, Tin VP, Suen WS, Wang E, Lam WK, Cai WW, Chung LP, Wong MP (2007) High resolution analysis of genomic aberrations by metaphase and array comparative genomic hybridization identifies candidate tumour genes in lung cancer cell lines. Cancer Lett 245: $303-314$ 